\title{
Do omega-3 fatty acids have a role in prevention of cardiovascular disease?
}

\author{
Thomas A. Barringer ${ }^{1,2 *}$ \\ 1 Heart and Wellness Clinic, Charlotte, NC, USA \\ 2 University of North Carolina School of Medicine, Chapel Hill, NC, USA \\ *Correspondence: tbarringer@novanthealth.org \\ Edited by: \\ George E. Billman, The Ohio State University, USA
}

As often the case within scientific research, the answer is not as straightforward as the question. In contradistinction to earlier data, recently published studies have been negative, and thus raised the question of whether supplementation with omega-3 fatty acids for prevention of cardiovascular disease is now passé. Some background knowledge is necessary to appreciate this perplexing and controversial topic.

Observational studies performed within the general population over the past 40 years have almost uniformly noted an inverse relationship between fatty fish or $n-3$ fatty acid consumption and morbidity or mortality from coronary heart disease (CHD; Kromhout et al., 1985, 2010, 2011; Dolecek, 1992; Rodriguez et al., 1996; Daviglus et al., 1997; Albert et al., 1998, 2002; Oomen et al., 2000; Iso et al., 2001; Yuan et al., 2001; Hu et al., 2002, 2003; Lemaitre et al., 2003; Mozaffarian et al., 2003; He et al., 2004; Panagiotakos et al., 2005; Mozaffarian and Rimm, 2006; Bjerregaard et al., 2010). Likewise, among studies which measured blood or tissue levels of $n-3$ fatty acids the majority have shown the same inverse correlation with cardiovascular disease events (Siscovick et al., 1995; Albert et al., 1998, 2002; Harris et al., 2007; Block et al., 2008; Park et al., 2009; Pottala et al., 2010). However, observational data can never prove cause-andeffect. Randomized clinical trials (RCT) have been designed specifically to provide a more controlled evaluation of the effects of omega-3 fatty acids treatment on adverse cardiovascular events. However, RCTs have their own limitations, especially when the interventional agent being tested is one that is available in food and consumed in varying amounts by the population participating in the trial. Among the vitamin supplement trials, for example, results derived from the whole study population have sometimes been opposite from the results from the "deficient" subpopulation (Morris and Tangney, 2011; Rimm and Stampfer, 2011).

There have been about 20 published trials in which patients were randomized to a daily dose of $n-3$ fatty acid vs. placebo and who were then followed for varying intervals in order to assess some type of cardiovascular disease outcome. Most of these were performed in patients with a history of CHD.

Two recently published meta-analyses reached divergent conclusions. Kwak et al. (2012) performed a meta-analysis of 14 trials, and concluded that there was insufficient evidence of a preventive effect of omega-3 fatty acid supplements against overall cardiovascular events among patients with a history of cardiovascular disease. The authors note that there was a small reduction in cardiovascular death (RR 0.91; 95\% CI: 0.84-0.99), which disappeared when one study with major methodological problems was excluded. Quality of a meta-analysis in predicated upon the quality of the individual studies and on the amount of heterogeneity among the studies. In this case, all but four of these trials had less than 600 participants, half lasted no more than a year, several were designed with angiographic endpoints, and three were performed in patients with implantable cardioverter-defibrillators (ICDs), using ICD discharges as the primary endpoint. General conclusions from such a metaanalysis are therefore highly speculative. The Agency for Healthcare Research and Quality also performed a systematic review with random effects meta-analysis
(EPC Technical Papers Series, 2012). They included RCTs of at least 4 weeks duration, using EPA + DHA supplementation less than $6 \mathrm{~g} /$ day. The summary relative risks for all-cause mortality (17 trials, 51,264 patients) and cardiovascular mortality (14 trials, 48,500 patients) were 0.95 (95\% CI: $0.89-1.01$ ) and 0.89 (95\% CI: 0.83-0.96), respectively. Whether you believe omega-3 fatty acid supplementation reduces cardiovascular mortality or not would seem to depend on which meta-analysis you prefer. However, since the studies included in both of these reviews are so diverse, a meta-analysis is not the most appropriate method to answer our question. A look at the differences among the large RCTs which were specifically designed to assess cardiovascular morbidity and mortality will shed more light, and at least clarify what are the unresolved issues.

Only eight RCTs have been of sufficient size $(n=2000-18,000)$ to provide adequate power for detecting statistically meaningful results (Kromhout et al., 1985, 2010, 2011; Burr et al., 1989; GISSI-Prevenzione Investigators, 1999; Yokoyama et al., 2007a,b; The GISSI-HF investigators, 2008; Galan et al., 2010; Rauch et al., 2010; The ORIGIN Trial Investigators, 2012). Trial designs, n-3 fatty acid doses, and study population characteristics were quite different. In summary, GISSI-Prevenzione Investigators (1999) and DART (1989) showed a large CV mortality benefit; JELIS (2007) showed a reduction in non-fatal CV events, but no effect on mortality; The GISSI-HF investigators (2008) showed a small mortality benefit in CHF patients; The ORIGIN Trial Investigators (2012), Omega (2010), AlphaOmega (2010), and SU.FOL.OM3 (2010) showed no CV benefits (fatal or non-fatal) in their overall trial results. It should also 
be noted that there are a few clinical and experiment studies in which omega-3 fatty acids adversely altered cardiac rhythm, but effects of omega-3 fatty acids on rhythm disturbances is a separate, albeit related, topic which will not be addressed here.

The most popular explanation for the divergent outcomes is the following: The trials showing the largest benefit were older, performed in the pre-statin era, which was also a time of fewer therapeutic options in general for the patient presenting with a CVD event (i.e., virtually no revascularizations in the acute coronary syndrome setting, less anti-platelet therapies, etc). Patients participating in the more recent trials had the advantage of much more aggressive interventions as well as drug therapies that have been proven to reduce recurrent event rates, especially the statin class. Therefore, the mechanism(s) by which omega-3 fatty acids formerly improved CV outcomes may simply have been obviated by the newer better therapies.

However, the divergent outcomes of the omega-3 studies published to date also raise the possibility that only certain subgroups of patients derive a cardiovascular benefit from taking omega-3 fatty acids. Factors which may be critical in identifying the most responsive subgroups, include the following:

1. Cardiac function - In GISSI-P there was an inverse association between ejection fraction (EF) and prevention of sudden death. GISSI-HF (mean EF 33\%) showed a $9 \%$ reduction in total mortality for HF patients (14\% reduction in those who were compliant with medication). Patients with mildly diminished cardiac function (EF 30-45\%), a group which were not systematically studied in the three negative post-MI trials (Omega, Alpha-Omega, and SU.FOL. OM3) and the one negative trial of dysglycemia patients (The ORIGIN Trial Investigators, 2012), might still be appropriate candidates for omega-3 therapy.

2. Baseline omega- 3 intake - In contrast to the results from the ORIGIN trial (all participants had diabetes or pre-diabetes), the Alpha-Omega sub-study of its 1,014 diabetic post-MI patients showed that the EPA + DHA group, compared to the placebo group, had a hazard ratio (HR) of 0.51 for death from CHD $(p=0.04)$, and 0.51 for ventricular arrhythmia-related events $(p=0.09)$. In addition, the EPA + DHA + ALA group had a HR of 0.16 for ventricular arrhythmia-related events, and a HR of 0.28 for ventricular arrhythmia-related events + fatal MI (Kromhout et al., 1985, 2010, 2011). Observational data have shown not only that EPA + DHA intake up to $200-250 \mathrm{mg} /$ day is associated with decreased cardiac, cardiovascular, or sudden cardiac death, but that no further reduction in fatal CHD occurs when EPA + DHA intakes exceed 200-250 mg/day (Mozaffarian and Rimm, 2006; EPC Technical Papers Series, 2012). Median baseline intake in ORIGIN was $210 \mathrm{mg} /$ day, in AlphaOmega it was 120-130 mg/day. A highbaseline intake of omega- 3 fatty acids is the reason various authors have proposed for why there was no CV mortality benefit observed in the JELIS trial, whose Japanese participants had baseline blood levels of EPA + DHA roughly 10 times higher than the average American level (Mozaffarian, 2007; Yokoyama et al., 2007a,b). It also explains why the control group in JELIS had a cardiac death rate per 1000 person-years of 2.5, while in GISSIPrevenzione it was 17 . It's likely that the baseline omega-3 intake (or more critically the tissue level, for which the estimated intake is a rough correlate) is another important factor in determining which patients will derive a benefit in prevention of (specifically) fatal CHD.

3. Baseline triglyceride (TG) levels ORIGIN patients had a median TG level of $140 \mathrm{mg} / \mathrm{dL}$. The Alpha-Omega subgroup of diabetic patients, in whom omega-3 fatty acid therapy reduced CHD death by $\sim 50 \%$, had a mean baseline value of $198 \mathrm{mg} / \mathrm{dL}$. The JELIS subgroup of diabetic/pre-diabetic patients, who had a $22 \%$ reduced incidence in CAD events in the omega-3 arm, had a mean TG value of $175 \mathrm{mg} /$ dL (Oikawa et al., 2009). The overall JELIS trial showed an inverse relationship between TG levels and benefit in $\mathrm{CV}$ event reduction, with no benefit in the subgroup with baseline TG levels $<150 \mathrm{mg} / \mathrm{dL}$ and HDL-C >40 mg/ dL. High TG and/or low HDL might possibly be a marker for who derives some CVD benefit from omega-3 supplementation.

4. Omega-3 dose - All of the large trials to date have used doses of $1 \mathrm{~g}$ or less per day, except JELIS, which although an open-label study, showed a 19\% reduction in non-fatal CV events. Therefore, what is the most effective dose remains an unanswered question that will not be resolved by any of the studies currently in progress (ASCEND, Rishio e Prevenzione, and VITAL, all of which use $<1$ g/day).

At this time, it is not possible to definitively answer our original question. The factors enumerated above may or may not explain the discrepancies observed in the omega- 3 trial outcomes, but each one formulates a reasonable hypothesis which needs to be addressed in future research. Otherwise, those who believe the latest research has now established that there is no role for omega-3 fatty acids in prevention of CVD may be throwing the proverbial baby out with the bathwater, and thereby deprive certain patients a potentially valuable therapy.

\section{REFERENCES}

Albert, C. M., Campos, H., Stampfer, M. J., Ridker, P. M., Manson, J. E., Willett, W. C., et al. (2002). Blood levels of long-chain n-3 fatty acids and the risk of sudden death. N. Engl. J. Med. 346, 1113-1118.

Albert, C. M., Hennekens, C. H., O’Donnell, C. J., Ajani, U. A., Carey, V. J., Willett, W. C., et al. (1998). Fish consumption and risk of sudden cardiac death. JAMA 279, 23-28.

Bjerregaard, L. J., Joensen, A. M., Dethlefsen, C., Jensen, M. K., Johnsen, S. P., Tjønneland, A., et al. (2010). Fish intake and acute coronary syndrome. Eur. Heart J. 31, 29-34.

Block, R. C., Harris, W. S., Reid, K. J., Sands, S. A., and Spertus, J. A. (2008). EPA and DHA in blood cell membranes from acute coronary syndrome patients and controls. Atherosclerosis 197, 821-828.

Burr, M. L., Fehily, A. M., Gilbert, J. F., Rogers, S., Holliday, R.M., Sweetnam, P.M., et al. (1989). Effects of changes in fat, fish, and fibre intakes on death and myocardial reinfarction: diet and reinfarction trial (DART). Lancet 2, 757-761.

Daviglus, M. L., Stamler, J., Orencia, A. J., Dyer, A. R., Liu, K., Greenland, P., et al. (1997). Fish consumption and the 30 -year risk of fatal myocardial infarction. N. Engl. J. Med. 336, 1046-1053.

Dolecek, T. A. (1992). Epidemiological evidence of relationships between dietary polyunsaturated fatty acids and mortality in the multiple risk factor intervention trial. Proc. Soc. Exp. Bio. Med. 200, 177-182.

EPC Technical Papers Series. (2012). Advancing the Role of Evidence-based Reviews in Nutrition Research and Applications. Volume 4: Effects of Eicosapentanoic Acid 
and Docosahexanoic Acid on Mortality Across Diverse Settings, Structured Abstract. Rockville, MD: Agency for Healthcare Research and Quality.

Galan, P., Kesse-Guyot, E., Czernichow, S., Briancon, S., Blacher, J., and Hercberg S. (2010). Effects of B vitamins and omega-3 fatty acids on cardiovascular diseases: a randomized placebo controlled trial. $B M J$ 341, c6273.

GISSI-Prevenzione Investigators (1999). Dietary supplementation with n-3 polyunsaturated fatty acids and vitamin $\mathrm{E}$ after myocardial infarction: results of the GISSI-prevenzione trial. Lancet 354, 447-455.

Harris, W. S., Poston, W. C., and Haddock, C. K. (2007). Tissue n-3 and n-6 fatty acids and risk for coronary heart disease events. Atherosclerosis 193, 1-10.

He, K., Song, Y., Daviglus, M. L., Liu, K., Van Horn, L., Dyer, A. R., et al. (2004). Accumulated evidence on fish consumption and coronary heart disease mortality: a meta-analysis of cohort studies. Circulation 109, 2705-2711.

Hu, F. B., Bronner, L., Willett, W. C., Stampfer, M. J., Rexrode, K. M., Albert, C. M., et al. (2002). Fish and omega- 3 fatty acid intake and risk of coronary heart disease in women. JAMA 287, 1815-1821.

Hu, F. B., Cho, E., Rexrode, K. M., Albert, C. M., and Manson, J. E. (2003). Fish and long-chain omega-3 fatty acid intake and risk of coronary heart disease and total mortality in diabetic women. Circulation 107, 1852-1857.

Iso, H., Rexrode, K. M., Stampfer, M. J., Manson, J. E., Colditz, G. A., Speizer, F. E., et al. (2001). Intake of fish and omega-3 fatty acids and risk of stroke in women. JAMA 285, 304-312.

Kromhout, D., Bosschieter, E. B., and de Lezenne Coulander, C. (1985). The inverse relation between fish consumption and 20-year mortality from coronary heart disease. N. Engl. J. Med. 312, 1205-1209.

Kromhout, D., Geleijnse, J. M., de Goede, J., Griep, L. M. O., Mulder, B. J. M., de Boer, M. J., et al. (2011). N-3 fatty acids, ventricular arrhythmia-related events, and fatal myocardial infarction in postmyocardial infarction patients with diabetes. Diabetes Care 34, 2515-2520.

Kromhout, D., Giltay, E. J., Geleijnse, J. M., and Alpha Omega Trial Group. (2010). N-3 fatty acids and cardiovascular events after myocardial infarction. $N$. Engl. J. Med. 363, 2015-2026.

Kwak, S. M., Myung, S. K., Lee, Y. J., Seo, H. G., and Korean Meta-analysis Study Group. (2012). Efficacy of omega-3 fatty acid supplements in the secondary prevention of cardiovascular disease. Arch. Intern. Med. 172, 686-694.

Lemaitre, R. N., King, I. B., Mozaffarian, D., Kuller, L. H., and Tracy, R. P. (2003). Siscovick DS. n-3 Polyunsaturated fatty acids, fatal ischemic heart disease and non-fatal myocardial infarction in older adults. The cardiovascular health study. Am. J. Clin. Nutr. 77, 319-325.

Morris, M. C., and Tangney, C. C. (2011). A potential design flaw of randomized trials of vitamin supplements. JAMA 305, 1348-1349.

Mozaffarian, D. (2007). JELIS, fish oil, and cardiac events. Lancet 369, 1062-1063.

Mozaffarian, D., Lemaitre, R. N., Kuller,L. H., Burke, G. L. Tracy, R. P., and Siscovick, D. S. (2003). Cardiac benefits of fish consumption may depend on the type of fish meal consumed: the cardiovascular health study. Circulation 107, 1372-1377.

Mozaffarian, D., and Rimm, E. B. (2006). Fish intake, contaminants, and human health: evaluating the risks and benefits. JAMA 296, 1885-1899.

Oikawa, S., Yokoyama, M., Origasa, H., Matsuzaki, M., Matsuzawa, Y., Saito, Y., et al. (2009). Suppressive effects of EPA on the incidence of coronary events in hypercholesterolemia with impaired glucose metabolism: sub-analysis of primary prevention cases from the Japan EPA lipid intervention study (JELIS). Atherosclerosis 206, 535-539.

Oomen, C. M., Feskens, E. J., Rasanen, L., Fidanza, F., Nissinen, A. M., Menotti, A., et al. (2000). Fish consumption and coronary heart disease mortality in Finland, Italy, and The Netherlands. Am. J. Epidemiol. 151, 999-1006.

Panagiotakos, D. B., Pitsavos, C., Zampelas, A., Chrysohoou, C., Griffin, B. A., Stefanadis, C., et al. (2005). Fish consumption and the risk of developing acute coronary syndromes: the CARDIO2000 study. Int. J. Cardiol. 102, 403-409.

Park, Y., Lim, J., Lee, J., and Kim, S. G. (2009). Erythrocyte fatty acid profiles can predict acute non-fatal myocardial infarction. Br. J. Nutr. 102, 1355-1361.

Pottala, J. V., Garg, S., Cohen, B. E., Whooley, M. A., and Harris, W. S. (2010). Blood eicosapentaenoic and docosahexaenoic acids predict all-cause mortality in patients with stable coronary heart disease: the heart and soul study. Circ. Cardiovasc. Qual. Outcomes 3 , 406-412.

Rauch, B., Schiele, R., Schneider, S., Diller, F., Victor, N., Gohlke, H., et al. (2010). OMEGA, a randomized, placebo-controlled trail to test the effect of highly purified omega- 3 fatty acids on top of modern guideline-adjusted therapy after myocardial infarction. Circulation 122, 2152-2159.

Rimm, E. B., and Stampfer, M. J. (2011). Folate and cardiovascular disease: one size does not fit all. Lancet 378, 544-546.

Rodriguez, B. L., Sharp, D. S., Abbott, R. D., Burchfiel, C. M., Masaki, K., Chyou, P. H., et al. (1996). Fish intake may limit the increase in risk of coronary heart disease morbidity and mortality among heavy smokers. The Honolulu heart program. Circulation 94, 952-956.

Siscovick, D. S., Raghunathan, T. E., King, I., Weinmann, S., Wicklund, K. G., Albright, J., et al. (1995). Dietary intake and cell membrane levels of long-chain n-3 polyunsaturated fatty acids and the risk of primary cardiac arrest. JAMA 274, 1363-1367.

The GISSI-HF investigators. (2008). Effect of n-3 polyunsaturated fatty acids in patients with chronic heart failure (the GISSI-HF trial): a randomized, doubleblind, placebo-controlled trial. Lancet372, 1223-1230.

The ORIGIN Trial Investigators. (2012). N-3 fatty acids and cardiovascular outcomes in patients with dysglycemia. N. Engl. J. Med. 367, 309-318.

Yokoyama, M., Origasa, H., Matsuzaki, M., Matsuzawa, Y., Saito, Y., Ishikawa, Y., et al. (2007a). Effects of eicosapentaenoic acid on major coronary events in hypercholesterolaemic patients (JELIS): a randomised open-label, blinded endpoint analysis. Lancet 369 , 1090-1098.

Yokoyama, M., Origasa, H., Matsuzaki, M., Matsuzawa, Y., and Saito, Y. (2007b). Reply to a letter to the editor. Lancet 370, 215-216.

Yuan, J. M., Ross, R. K., Gao, Y. T., and Yu, M. C. (2001). Fish and shellfish consumption in relation to death from myocardial infarction among men in Shanghai, China. Am. J. Epidemiol. 154, 809-816.

Received: 14 September 2012; accepted: 14 September 2012; published: 05 October 2012.

Citation: Barringer TA (2012) Do omega-3 fatty acids have a role in prevention of cardiovascular disease? Front. Physio. 3:395. doi: 10.3389/fphys.2012.00395

This article was submitted to Frontiers in Cardiac Electrophysiology, a specialty of Frontiers in Physiology.

Copyright (c) 2012 Barringer. This is an open-access article distributed under the terms of the Creative Commons Attribution License, which permits use, distribution and reproduction in other forums, provided the original authors and source are credited and subject to any copyright notices concerning any third-party graphics etc. 